\title{
Article
}

\section{Professional judgement and decision making in adventure sports coaching: The role of interaction}

Collins, L., and Collins, D.

Available at http://clok.uclan.ac.uk/12585/

Collins, L., ORCID: 0000-0002-7478-1140 and Collins, D. ORCID: 0000-00027601-0454 (2016) Professional judgement and decision making in adventure sports coaching: The role of interaction. Journal of Sports Sciences, 34 (13). pp. 1231-1239. ISSN 0264-0414

It is advisable to refer to the publisher's version if you intend to cite from the work. http://dx.doi.org/10.1080/02640414.2015.1105379

For more information about UCLan's research in this area go to http://www.uclan.ac.uk/researchgroups/ and search for <name of research Group>.

For information about Research generally at UCLan please go to http://www.uclan.ac.uk/research/

All outputs in CLoK are protected by Intellectual Property Rights law, including Copyright law. Copyright, IPR and Moral Rights for the works on this site are retained by the individual authors and/or other copyright owners. Terms and conditions for use of this material are defined in the policies page.

\section{CLoK}

Central Lancashire online Knowledge www.clok.uclan.ac.uk

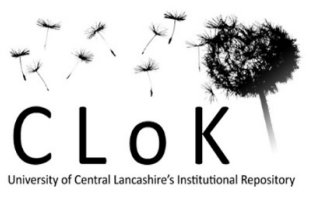


This is a pre-proof corrected manuscript, as accepted for publication, of an article published by Taylor \& Francis in Journal of Sports Sciences on $30^{\text {th }}$ October 2015, available online at: http://www.tandfonline.com/doi/full/10.1080/02640414.2015.1105379

Professional Judgement and Decision Making in Adventure Sports Coaching: The Role of Interaction

Loel Collins* and Dave Collins

Institute for Coaching and Performance, University of Central Lancashire, Preston, UK

*Correspondence concerning this article should be addressed to Loel Collins, Institute for

Coaching and Performance, University of Central Lancashire, Preston, UK, PR1 2HE. Email: lcollins2@uclan.ac.uk. 


\begin{abstract}
This qualitative study presents the view that coaching practice places demands on the coach's adaptability and flexibility. These requirements for being adaptive and flexible are met through a careful process of professional judgement and decision making based on contextappropriate bodies of knowledge. Adventure sports coaches were selected for study on the basis that adventure sports create a hyper-dynamic environment in which these features can be examined. Thematic analysis revealed that coaches were generally well-informed and practiced with respect to the technical aspects of their sporting disciplines. Less positively, however, they often relied on ad-hoc contextualization of generalised theories of coaching practice to respond to the hyper-dynamic environments encountered in adventure sports. We propose that coaching practice reflects the demands of the environment, individual learning needs of the students, and the task at hand. Together, these factors outwardly resemble a constraints led approach but, we suggest, actually reflect manipulation of these parameters from a cognitive rather than an ecological perspective. This process is facilitated by a refined judgement and decision-making process, sophisticated epistemology and an explicit interaction of coaching components.
\end{abstract}

Keywords: Coach education, Constraint manipulation, explicit interaction 


\section{Professional Judgement and Decision Making in Sports Coaching: The Role of Interaction}

Research has highlighted that coach behaviour is (or should be) a subtle blend of components designed to provide a bespoke solution to the specific challenges of coaching context (Abraham \& Collins, 2011; Martindale \& Collins, 2005, 2007, 2010, Collins \& Collins, 2012,2013, 2014, 2015). These authors have suggested that the process through which this optimum blend is derived is a combination of nested decision making processes referred to as Professional Judgement and Decision Making (PJDM). We identify that the quality of coaching output depends on the coach's PJDM prowess, coupled with his/her access to the components of knowledge necessary for that particular challenge, including (but not limited to) pedagogy, emotional intelligence, and interpersonal skills. Coaches are generally well informed and practiced with respect to the technical aspects of their sporting disciplines and have highly developed knowledge schemas in relation to the technical performance. In this regard, the schemas can be thought of as structures of knowledge pertinent to the particular topic, with the hierarchic and nested nature of the knowledge playing an important role in decision making and action. An example may be the way in which a forward paddling stroke (the overall schema) may be varied (the knowledge nested within) to generate different movements of the kayak.

In addition, schemas are developed in relation to the pedagogic aspects of the coach's role, and these inform the coaching practice in the form of procedures, structures and routines. An example here may be an overall schema on say, demonstration, which encompasses nested knowledge on how different methods can generate various outcomes. However, coaches often rely on ad-hoc and opportunist contextualization of generalised coaching theories to refine those knowledge schemas (Collins \& Collins, 2014) or, even worse, utilise a recipe approach ("in this context, do this...") perhaps as a consequence of an 
overly competency-focused method of training (cf. Collins, Martindale, Burke, \& Cruickshank, 2014). As one of several consequences, coach behaviour may be suboptimal, as the solution derived from PJDM may be based on insufficiently detailed knowledge or a "convenience" compromise brought about by time or environmental pressures; that is, a compromise which insufficiently considers the interaction of factors in that particular context. Our point here is that, especially in complex environments which characterise interpersonal interactions such as coaching, 'satisfycing' can lead to an overly simple solution be generated which has failed to consider the various factors in sufficient depth or breadth (Mascarenhas \& Smith, 2011).

These problems can occur for a variety of reasons, which likely interact to make addressing them even harder. For example, coaches may be sufficiently open-minded or flexible to consider solutions which they have seen in other coaching environments. Without an in-depth knowledge of the underpinnings and interactive impacts of such actions, however, they are often unable to transfer the good features of the solution (to be adaptable) or even to transfer these aspects to come up with a set of novel but even more effective methods (to be creative) (Collins, Martindale, Burke, \& Cruickshank, 2014). As such, our paper is about the drive to develop flexible, adaptable and creative coaches; an aim which is certainly relevant for coaches who specialise in adventure sports and, we would suggest, generically as well.

\section{Professional Judgement and Decision Making in Coaching}

Abraham and Collins (2011) and Collins and Collins (2013, 2014) identified that PJDM acts to synergise the complex pedagogic skills associated with coaching practices. In coaching, this PJDM process should enable the coach to make best use of his/her skillsets by designing, deploying, and refining teaching strategies; planning programmes; linking sessions and responding to performer demands during those sessions. In responding to the individual 
needs of a performer the coach is required to adapt and modify the coaches existing skills to meet he demands of an individual performer. As such, PJDM is proposed as a mechanism to develop adaptability and creativity within the coaching process.

This PJDM in coaching requires a base of declarative knowledge, coaching skills, and planning, as well as an established philosophical underpinning (Collins, Collins, \& Grecic, 2014), in order to realise optimal benefits. Consequently, amongst the skills we hypothesise to be present is the ability to respond quickly and efficiently to selected (or preselected) subsets of factors encountered in the session. To achieve adaptability_and creativity, the fundamental components of the base knowledge should be combined and integrated in response to the demands of the coaching situation. The specifics of the relationship, how one component influences the other and how those influence the decisions in that coaching context, lies at the heart of good coaching practice. Developing understanding of the interaction between the fundamental components deepens our comprehension of the PJDM process and, once synthesised and formally developed, can enhance the education of both Adventure Sports Coaches (ASC) and coaches in general.

\section{Coaching: A Question of Relationship, Not Just Content}

Uniqueness in any coaching environment lies in the complexity of the interactional relationship between already linked, such as timing and structure of feedback and potentially discrete components such as venue choice of the coaching process (Collins \& Collins, in review). In short, it is not so much the different skills required but rather, how they interact to generate an optimum solution to a coaching challenge. The notion of interaction helps to explain components of the coaching process and furthers our understanding of PJDM. Interactions in a coaching context involve cognitive structures that incorporate the relationships between different components of the coaching process utilising the knowledge schema (Tannen \& Wallat, 1987) required for the face-to-face, interpersonal coaching 
encounters, and an understanding of the interaction framing/context (Tannen \& Wallat, 1987) in which that knowledge schema is applied. Thus, the coaching process is built on both a suitable declarative knowledge (i.e., technical and pedagogic; Collins \& Kusch, 1998) and the complex connections between that knowledge, the environment and the individual student. The ability to adapt requires more than mere replication of predefined responses; rather, it is more an application of declarative knowledge in creative and flexible ways that reflect the context of application.

\section{Why Adventure Sports and the Adventure Sports Coach?}

\section{Adventure sports}

Adventurous sports present many challenges for the coaches. Most notable of these challenges is "what is an adventure sport?" Long held views on the significant level of risk in adventure sports are unfounded with many non-adventure sports being riskier. Equally, views regarding motivation as a thrill or sensation seeking behaviour (Vallerand, 2004; Zuckerman, 1994) only serve to go part way to clarifying motivation for a particular demographic and are acknowledged as increasingly limited (cf: Brymer \& Grey, 2010). Three aspects of AS and its coaching have emerged in recent research (Collins, 2014) that shed light on the complexities faced by Adventure Sports Coaches (ASCs).

Firstly; AS differ from other sports in respect to the rules that govern participation. In traditional sports, the 'rule book' is written and adhered to by those playing the game; indeed, a referee is frequently employed to ensure the rules are adhered to. AS have rules that are constructed by the individual participants, these evolve and develop in a fluid manner and are policed by the participant. The exact terms under which a participant participates are highly individualised.

Secondly, the nature of the environment in which the sport is practiced has to be considered. In competitive sports, effort is made to ensure a level playing field is assured for 
all competitors. We see this in the use of artificial white water courses for kayak slalom competition, climbing walls in competitive climbing competition and manufactured free-ride courses in skiing competition. This is essentially a 'managing out' of some dynamic elements of the environment that cause inconsistency and unfairness between athletes. Crump's (1991) notions of 'sportification' come into play and this leveling process evolves to a point that the governing bodies and, presumably, competitors accept as reasonable for competition between athletes. At the other limit, ASs take place in highly dynamic and literally relentless environments, The temperature, wind and remoteness in artic conditions cannot be turned off , a referee whistle will not stop the game! Conversely andreflecting the personalised nature of adventure, climbing walls, pisted ski runs and artificial white water courses are sufficiently dynamic to be adventurous for some. This raises notions of the commodification of adventure discussed by Loynes, (1996) and the selling of safe adventure, which has contributed to the confusion over the part risk plays. Identifying the level of adventure for each individual represents a significant challenge for the ASC a factor compounded by the cognitive load on the ASC (Collins \& Collins, 2013; Brown, 2000) who is making judgements on security and safety that the participants is unable to make.

Thirdly, AS are characterised by a very dynamic environment with, epistemologically, a much broader range of options apparent for both coaches and participants. In coaching terms Collins, Collins \& Grecic, (2014) identified that the end objective of adventure sports coaches may differ from other sports coaches: a sample of high level ASC had a clear focus to develop a performance that is independent of the coach at a level of adventure appropriate to the individual. These philosophical differences appear to require the ASC to have a very broad range of teaching skills and approaches, some of which are common with other sports coaches and some that are highly contextual to adventure sports (Collins \& Collins, 2012, 2013, 2014a, 2014b, 2015a, 2015b). Specifically those 
ASCs have a positive view of risk, utilize risk as a pedagogic tool and maintain a learning focus in the coaching process which reflects the need for the performer to adapt and refine their own performance in the adventure setting when they do not have access to a coach. This final point may go some way to explain why ASCs do very little high performance development coaching; i.e. the student has achieved independence from the coach, technically, tactically and pedagogically (cf. Jones 2007). Some definitions of coaching would not describe the activity of ASCs as coaching (Cross \& Lyle, 1999) we take an open view of coaching and align more closely with Jones, (2007) of the coach as a broader developer of skills and the individual. In particular the focus of the coaching process is not purely development of performance but development of independence in an adventurous context.

In short, Adventure sports have individualised rules, are policed by the participants and take place in environments that are relentless and highly dynamic. The ASC develops independent performers within those terms.

\section{Adventure Sports Coaches}

Collins and Collins (2012) conceptualised adventure sports coaching (ASCg) as a subgroup of traditional coaching practice and outdoor education. The ASC shares skills with both coaching and educational colleagues, has a refined PJDM process (Collins \& Collins, 2013), and has an identifiable epistemological framework (Collins et al., 2014). This investigation focussed on the behaviour and post-session rationalisations of high-level ASCs. We hypothesised that linear (procedural) and cross factor (dendritically linked) themes characterise that interaction. Specifically, we were interested in the ways in which ASCs arrive at optimal decisions by exploiting that interaction and manipulate parameters in the AS environment.

\section{Method}




\section{Participants}

Data sources included interviews with seven expert British ASCs $\left(M_{\mathrm{age}}=50.3, S D=\right.$ 9.1), together with video and semi-structured interviews related to 14 (two per participant) non-related sessions of ASC practice. Inclusion criteria were as follows: (a) holding multiple British Canoe Union Coach Level 5 (the highest available) awards and/or national coaching roles across different canoeing disciplines; (b) currently actively engaged in ASCg activity; (c) active as an ASC educator; (d) willing to reflect on coaching practice; (e) holding a coaching qualification in at least one other AS; and (f) availability. No incentive was offered for participation. All identifying information was removed from transcripts to protect anonymity. Purposive sampling was used to select participants with seniority and experience in order to generate a picture of high-level practice. Coaches had a combined 157 years of ASCg experience in kayaking, canoeing, mountaineering, climbing, mountain biking, and skiing. The coaches enjoyed high status reputations within the field and were all active as participants in AS and ASC education. In the absence of more effective or objective markers (cf. Nash, Martindale, Collins, \& Martindale, 2012), we were confident that this sample presented a picture of good practice and high-level coaching performance in AS.

At the time of writing, the primary investigator was a 49 -years-old male with 30 years of experience as an AS coach within National Centres in the United Kingdom. He was a coach educator for the British Canoe Union and holds the British Canoe Union's Level 5 Coach award in four disciplines. He is a qualified mountaineering and ski instructor and holds a doctorate in ASCg practice. The researcher had good rapport with the participating coaches.

\section{Procedure}

Following ethical approval from the university, the investigation followed a three stage cycle: pre-session (semi-structured) interview, observation and video of session and 
post-session interview; the cycle was repeated twice. This generated a videotext for each of the sessions observed (Collins \& Collins, 2014). Interview guides were constructed and piloted with three other coaches of similar qualification and experience to the sample group. The prompts were modified before use (see Table $1 \& 2$; Smith, 2011a) in response to feedback from the pilots. The final guides were used to scaffold the interview process; however, depending on the breadth and depth of responses provided, the questions were not always utilized or asked verbatim (Denzin \& Lincoln, 2005; Smith, Flowers \& Larkin, 2012). Questions emerging in the first cycle could be re-examined in the second cycle allowing emergent themes to be explored, revisited, and reconsidered. The structured interviews varied in length $\left(M_{\text {duration }}=86 \mathrm{~min}\right)$; participants agreed upon the time and location of interviews. Interviews were digitally recorded and transcribed using a commercial transcription service. Sessions were video recorded using synchronised discrete Hero2HD body/chest mounted cameras, one worn by the participating coach and the second by the researcher who observed the session. A body mounted point of view camera was considered less obtrusive than a hand-held or head mounted. This unobtrusive approach to using video is important as the process of being observed by a camera can alter behaviour (Foucault, 1991; Cromdal, 2000; Sparrman, 2005). Use of body mounted video also allowed for authentic participant observation of the video during the interview and facilitated accurate and deeper responses from the interviewee (Collins et al 2014; Spradley, 1980). Video stimulated recall of the session during the interview allowed for greater richness and depth in the data (Cohen \& Manion, 1994; Lyle, 2003; Muir \& Beswick, 2007; Rosenstein, 2002).

Table 1

Pre-Session Interview

Question

Probe

Aim - What are we interested in? 
Who are we "working"
with?

What do you know about this group?
Size of group, gender

Experience

Aims objectives

Ability

Motivations

Depth of knowledge "gleaned"

from group

Observation, questioning,

booking details

Individual's within group

The Session Plan(s)

What kind of planning have you done for this session?

What factors have you included in your plan?

Why?

How have you decided to focus the session? Why?

How has this been incorporated into you planning?
Flexibility Adaptability

Focus

Factors in plan

Environment Conditions/ Location

Individuals v's Group

Equipment \& Logistics

Experience

Training / CPD

Learning Environmnet

Reflection

When did planning happen

Extent of Plan
How much detail on the individuals?

How much based on experience

How much based on assumption?

How in information gathered in adventure sports coaching?

How extensive is the plan? How fixed is the plan? Can it be adapted? If not, why not?

What are the coach's, aim and objectives?

What factors shaped these?

The PJDM Process in Pre-Planning

What factors affect how
you made your judgments
and decisions regarding
the plan?

What effects do you anticipate your preplanning and PJDM will have in the session?
Understanding of DM

Adaptation

Learning from reflection/intuition/ experience

Psychological/behavioural development

Performance development Other support Awareness of different agendas Awareness of complexity - needs analysis
What is the coach's main area in which they make PJDM

Is there a focus or priority in this PJDM?

Does this relate to session aims and objectives What factors does the coach place value on? How do they arrive at that prioritisation? 


\begin{tabular}{ll}
\hline Contact time & What external factors affect \\
Location/conditions & the DM methods used? \\
Experience of students & $\begin{array}{l}\text { Is there a flexible } \\
\text { Personality }\end{array}$ \\
Student goals & \\
Safety & \\
Logistics & \\
Short-, mid-, and long-term goals & \\
\hline
\end{tabular}

Table 2

Post-Session Interview

\begin{tabular}{ccc}
\hline Question & Probe & $\begin{array}{c}\text { Aim }- \text { What are we } \\
\text { interested in? }\end{array}$ \\
\hline
\end{tabular}

The Session

What do you think where the key/ pivotal moments of the sessions? Why?

Of these "moments" what where "thought" moments? Why? Act-on, store, or ignore?

What where the "act-on" moments?

Are these the points? (use videos)

Is this kind of incident always this critical? Why? How?

What would make them different?

Why? How?

Which do you feel was the most critical? Why? How?

Impact and Reflection

How effective was your PJDM today?

How did you "create time" to make these calls?

Why? How?
Range and scope

Observation

Time

Safety/risk

Perceived arousal level

Conditions, changing

conditions, predicted or

other wise

Fatigue immediate and long term

Attention/motivation

Stage of learning

Success/failure

Parallel, linked, nested agendas

Individualised or group

focused

Profile building, how?

Tuition or Intuition

Mixture of ...

Specific interaction of ...

Act, store, ignore

information...

At a sessional level and/or

long term

Self efficacy

Confidence

Techniques

Skill level

Independence
What are the coaches' main areas of focus?

What factors does the coach place value on? What factors does the coach respond to? What factors does the coach "store"?

What factors are ignored?

Is a single approach to

PJDM used?

How did it alter?

Why did it alter?

Professional influence

Judgement (intuition)

Decision

(reasoned/logical)

It this linear or non linear, Duality, parallel, multiple, conflicting agendas in process?

Recall of sessions?

How does the coach assess success/impact of PJDM? Are they aware of nested agenda?

Are they aware of parallel agendas? 


\begin{tabular}{|c|c|c|}
\hline $\begin{array}{l}\text { How were these PJDM } \\
\text { influenced by the decisions } \\
\text { made earlier? } \\
\text { How will today's session } \\
\text { influence other sessions? } \\
\text { This week, next week, next } \\
\text { month. Why? }\end{array}$ & $\begin{array}{l}\text { Quality of paddler's } \\
\text { decision making } \\
\text { Retention of client/skill } \\
\text { Reflection pre, in, and on } \\
\text { action } \\
\text { Time management } \\
\text { Decisions prior to next } \\
\text { session } \\
\text { Tuition or intuition } \\
\text { Mixture of . . . } \\
\text { Specific interaction of ... }\end{array}$ & $\begin{array}{l}\text { Are they aware of duel } \\
\text { strategy? } \\
\text { What are the goals/impacts } \\
\text { and why are they selected? } \\
\text { Extent of reflective } \\
\text { practice } \\
\text { Practical time } \\
\text { management } \\
\text { Anticipation } \\
\text { Pre-plan for next session } \\
\text { Nested reflection/thinking } \\
\text { Parallel thinking agendas } \\
\text { Meta } \\
\text { cognition/components } \\
\text { Linear (procedural) } \\
\text { dendritic (Schematic/ } \\
\text { episodic) thinking routes } \\
\text { Adaptive expertise? }\end{array}$ \\
\hline
\end{tabular}

\section{Data Analysis}

Video texts were reviewed by the first author using the procedures suggested by Aronson (1994), Braun and Clarke (2006), and Fereday and Muir-Cochrane (2006). Initially, the videotexts where read and corrected while listening to the original digital recording; this was intended to help imagine the participant's voice and to assist in a more "complete analysis" (Smith, Flowers, \& Larkin, 2009, p. 82). During subsequent readings, videotexts were reconsidered in terms of common, recurring, underlying, and connecting themes (Miles \& Huberman, 1994). As themes emerged, they were grouped and categorised as appropriate. All coded data were then reviewed, relationships were highlighted, and a thematic map generated and utilised to guide following reanalysis of the video texts. The interactional themes, internally and externally coherent patterns, relationships could be further defined and refined until a thematic table could be constructed (Table 3; Axelrod, 1976; Crabtree \& Miller, 1999; Tolman, 1948).

The thematic analysis method adopted in this study was a hybrid of approaches, incorporating an inductive, data-driven method (Boyatzis, 1998); the use of themes (Crabtree 
\& Miller, 1999); and the identification of interactional links between those themes (Axelrod, 1976; Busch, Richards, \& Dampney, 2001, 2003; Tolman, 1948) and has been utilised in other studies of ASC practice (Collins \& Collins, 2014; Collins, Collins \& Grecic, 2014). The dendritic nature of the links between the themes is highlighted in the discussion narrative. For cases in which the coach could not fully articulate an interaction, this was "teased out" and made explicit in the interview process.

To enhance the study's trustworthiness, bracketing was utilised (Morrow, 2005). A reflective and reflexive commentary was maintained throughout the process, and the influence of personal values during the interviews and analysis was considered (Smith, 2011). The bracketing process enables the "essence of an experiential structure to be intuitively grasped and isolated" (Loland, 2007, p. 107). Systemic reflection enables the researchers to "bring to light ... hidden meanings and qualities" (Loland, 2007, p. 107). In this study, systematic reflection allowed the researcher to adapt the semi-structured interview in response to participants' responses. Triangulation of data from interviews and video enhanced the credibility of findings (Morrow, 2005).

External and internal member-checking was utilised post-analysis to guard against misinterpretation and researcher subjectivity, and to increase credibility (Morrow, 2005). The participating coaches provided internal member checks (Sparkes, 1998) and two independent investigators, an academic colleague and practitioner colleague in the AS field, served as external auditors and provided feedback on the themes generated. Meaning was coconstructed and reflected the broadly pragmatic and constructivist beliefs held by the authors. In cases where this step identified a disagreement between members of the collaborative research team, each investigator reread the original transcript, discussed the coding, and a consensus was reached on the interaction or themes identified.

\section{Results}


Initial analysis identified 413 individual primary themes and 106 codified units.

These units were subsequently grouped into 28 lower order, 12 mid-order, and 4 higher order themes and are summarised in Table 3. Higher order themes were then discussed in the context of a potential for interaction in which connective themes where identified that linked the high order themes. These connective themes emerged during the analysis and reanalysis of the data and formed the focus of the discussion in this paper.

\begin{tabular}{|c|c|c|c|}
\hline Cross factor Themes & $\begin{array}{c}\text { High order } \\
\text { Themes }\end{array}$ & $\begin{array}{c}\text { Mid order } \\
\text { Themes }\end{array}$ & Low order themes \\
\hline \multirow{8}{*}{$\begin{array}{l}\text { Mental Model of } \\
\text { Interaction } \\
\text { (Individual, in } \\
\text { context, performance) }\end{array}$} & Risk and benefit & $\begin{array}{l}\text { Individual } \\
\text { Development }\end{array}$ & Understanding \\
\hline & & & $\begin{array}{l}\text { Short term } \\
\text { Mid term } \\
\text { Long term }\end{array}$ \\
\hline & & Personality & $\begin{array}{l}\text { Non contextual } \\
\text { Contextual }\end{array}$ \\
\hline & $\begin{array}{l}\text { Independent } \\
\text { performance }\end{array}$ & Task & Technical \\
\hline & & & Physiological \\
\hline & $\begin{array}{l}\text { Interaction with } \\
\text { Environment }\end{array}$ & & Psychological \\
\hline & & & Tactical \\
\hline & & $\begin{array}{l}\text { Contextual } \\
\text { (Environment) }\end{array}$ & $\begin{array}{l}\text { Independent } \\
\text { learning } \\
\text { Independent } \\
\text { performance } \\
\text { Personal construct } \\
\text { of 'adventure' }\end{array}$ \\
\hline Environment & $\begin{array}{l}\text { Interaction with } \\
\text { Individual and task }\end{array}$ & $\begin{array}{l}\text { Physical } \\
\text { Environment } \\
\text { (Risk) }\end{array}$ & $\begin{array}{l}\text { Arousal } \\
\text { (Motivation, } \\
\text { sensation seeking) } \\
\text { Perception of risk } \\
\text { (Response) } \\
\text { Understanding or } \\
\text { environment }\end{array}$ \\
\hline
\end{tabular}




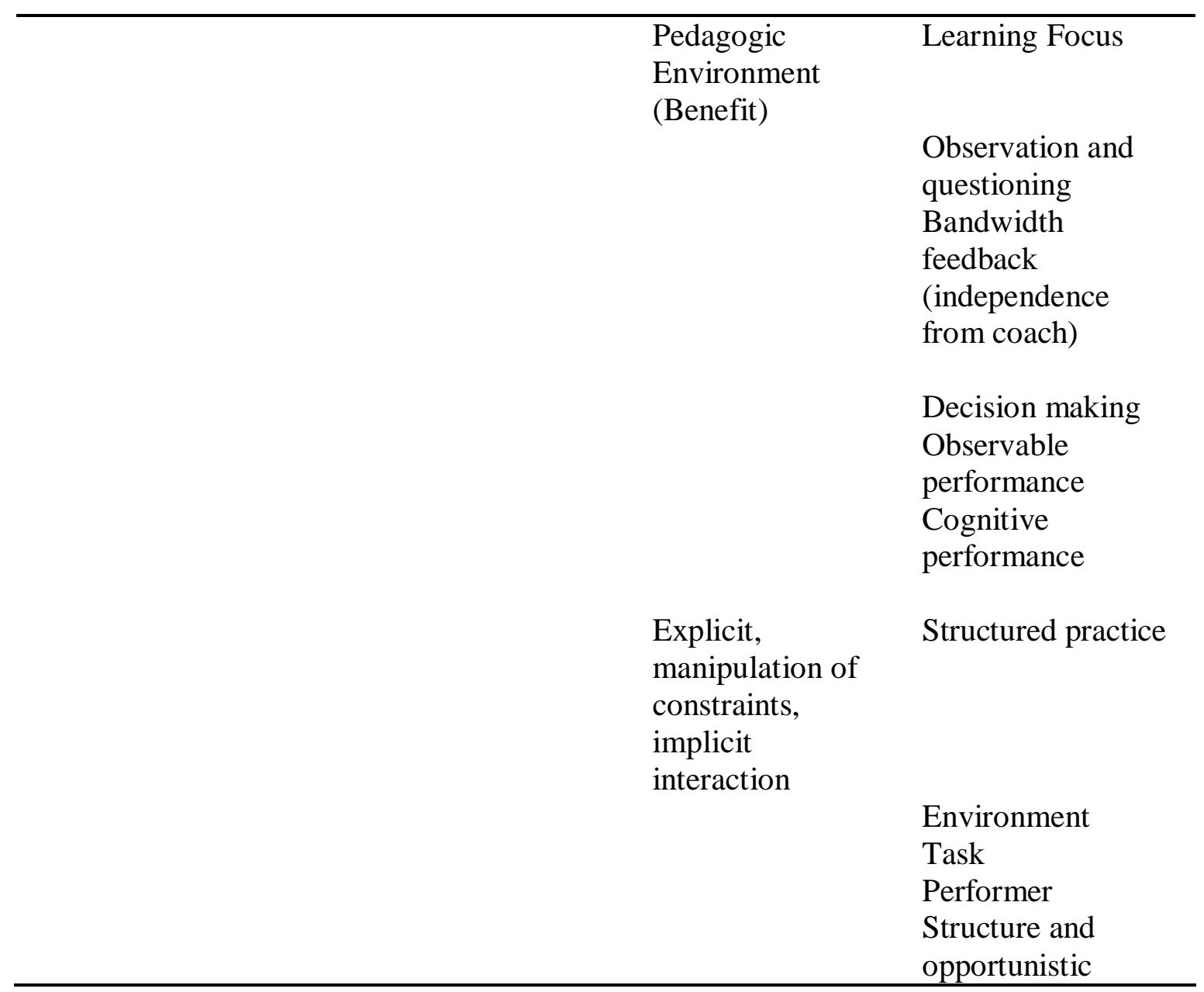

\section{Discussion}

Two types of connective themes emerged: explicit and tacit. Explicit connective themes were identified based on statements in which multiple components of the coaching process were articulated; for example, "The interaction of the student with the environment" (Coach 2). Tacit connective themes also emerged during the interview and analysis. These tacit themes were identified on the basis of frequency, significance, and emphasis. The high incidence of connective themes appears to support the notion of an interaction. As may be expected, explicit and hierarchical connective themes emerged to link lower, mid and higher order themes. Alongside these hierarchical links the interrelationship of themes of the same order also emerged generating a complex and dendritic map of links.

\section{Interaction Frame and Context}


The coaching environment (i.e., an outdoor adventurous setting) emerged as a supraordinate theme on the basis of its relationship to risk, created by the environment and the potential benefits of a proposed activity or course of action, as perceived by the coach and student. This supra-ordinate theme reflected the primacy of risk management in the decision making process in ASC. Within this supra-ordinate theme, two subordinate themes emerged: physical context, which is explicitly linked to risk; and pedagogic context, which is tacitly linked to benefit, the risk versus benefit decision echoing previous research (Collins \& Collins, 2013). Coach 2 stated this clearly: "You can twiddle your paddle all you want, but if you don't know the environment you're in for a beating." This is supported by Tannen and Wallat's (1987) notion of the interactional frame.

Traditionally, ASC education has given a high value to the practical management of risk, so the coach's ability to articulate that aspect is not surprising. Notably, however, the implicit benefits (i.e. outcomes against the objectives of the session; for example, skill development, adventurous experience, etc.) had to be unpacked during the interview, suggesting that the risk-benefit decision may be, at least in-part, tacit in nature (Collins \& Collins, 2013). Given the centrality of the risk-benefit decision, coach education appears to be focused on the collection (risk assessment) rather than application (risk and benefit assessment) of coaching knowledge. Perhaps related to this shift, coach education seems to focus on competency in specific skills (e.g., constructing a risk assessment) as opposed to the ability to demonstrate "practical wisdom" (e.g., a risk-benefit decision) having expertise in utilising the risk assessment via a risk benefit decision that utilises PJDM. This is consistent with the notion proposed by Collins and Evans (2007) that interactional expertise is a component of expertise in general. This supports a shift in the emphasis on replication in coach education to application; an explicit philosophical shift in curriculum content.

\section{The Environment}


The interaction of components in the PJDM process in ASC in particular (Collins \& Collins, 2014) always had an environmental reference. In this respect, the environmental reference acts as the overarching factor and directly links to the central risk-benefit decision mentioned earlier (Collins \& Collins, 2013). The coaches explicitly recognised this interaction using phrases such as "it's all in the venue choice" (Coach 4) and "it depends on what the water's doing" (Coach 1), "that relates to how intimidated the student feels" (Coach 3), and "he isn't flexible enough to roll that way, so I'll teach him a different roll for short term success and encourage him to do some stretches for some longer term stuff' (Coach 5). In discussing a sea kayaking session, Coach 4 explained why particular judgments were made:

That wasn't appropriate with them because they were at the stage where they needed me to give them technical input [stage of learning of the individual], so sending them away for a much longer distance wouldn't have been right. Also the environment-if I'd made it any longer [the session], they would've come out of the shelter and into the wind

When asked why this was problematic, Coach 4 responded, "It would be supervision rather than what I was attempting to do [coaching]." Coach 4 further highlighted that such a "shift" would alter the group management by affecting the span of control in the session, as the environment becomes more significant in the PJDM process the focus of the session would shift towards direct safety management and supervision.

\section{Parameter manipulation as part of the coaching process}

The focus in ASC is the manipulation of the environmental parameters: this differs from a more traditional focus on the management of task that is predominant in other context (Vickers, 2007; Collins \& Collins, 2012). Secondly and importantly, the cognitive paradigm underpins the decision making processes in regard to parameter manipulation: namely, the 
generation of effective knowledge schemas via an explicit structuring of practice to become increasingly variable. Coach 5 specifically states "I wanted them [the students] to start adapting the SPANGLE to new eddylines". Coach 5 is using his own terminology, that he has shared with the students, to highlight the relationship between speed and angle in a particular white water manoeuvre. Coach 5 later explains that this approach has developed from a recent understanding of principles rather than procedures that allow him to maximise this approach. In doing so he explicitly addresses the thinking and reflective processes required to adapt and select the principles into a different environment. This was justified on a clear information processes basis (schema development, memory etc.). Manipulation of the parameters as an element of good coaching in this context applies in all coaching practice and can, we suggest, clearly be utilised from a range of different coaching paradigms. PJDM emerges as the tool to manipulate parameters and also the mechanism of linking theory to practice in a highly pragmatic manner in which theories are adapted to suit the coaches need.

\section{Coaching: A Question of Relationship, Not Just Content}

Based on the importance of PJDM, the why of coaching and the interactions between factors which must be grasped for optimum exploitation, it is worth considering how these ideas may be incorporated into coach development systems. Rossi and Cassidy (1999) found that formal training had a low impact on coach education, whilst Marsick and Watkins (2001) recognised informal learning as a viable alternative to formalised approaches. Collins (2012) attributed the strength of informal learning to exposure to a community of practice and argued that this exposure gives access to the tacit, explicit, and interactional knowledge held within the field. Consequently, it is not surprising that Gilbert and Trudel (2004) reported that coaches appeared not to value formal education; rather, they preferred informal learning gained via applied practice, mentoring, apprenticeship, and reflection. The coach responses highlighted earlier appear to be a tacit recognition of the need for interaction and PJDM 
between the knowledge and its application, in addition to the knowledge itself. In exploring the interactions and PJDM as explicit features within formal settings, and coach education courses in particular, we might be able to increase the perceived value of formal coach education as well as the actual benefit to trainee coaches.

Reflecting this philosophical void, formal coach education (as suggested by course syllabi) seems to not focus — explicitly or perhaps even implicitly—on judgment and decision making. This leaves coaches to contextualise the pan-sport theories espoused in training (Saury \& Durand, 1998) and to develop the interactional expertise (Collins \& Evans, 2007) in an ad-hoc way. The PJDM and interactional components of practice in ASCg are frequently addressed via prerequisite experience between training and assessment. Concerningly, however, training infrequently addresses the need for reflective skills to maximise that experience. This ad-hoc position has clear weaknesses: Namely, the value of this apparently crucial constructed/contextualised knowledge is dependent upon personal interpretation of experience. As such, it is dependent upon the effectiveness of the coach's own reflective process, breadth of experience, and willingness to act on his or her own findings. Clearly, therefore, the coach requires a broad-ranging experience, skills in reflection, critical thought, and the ability to contextualise and transfer knowledge in a coherent and consistent manner (Collins \& Evans, 2007). In the absence of these characteristics, and until ideas such as interaction are enshrined in the content and philosophy of formal coach education courses, we are bound to produce sub-optimum or even downright dangerous ASCs!

Coaching by nature is dynamic and contextual, which does raise a question regarding the suitability of generalized coach education. In this study, ASC utilised the same coaching "tools" as other coaches, but the application differed reflecting the hyper-dynamic context. Currently, the contextualisation of pan-sport coaching practice happens in an ad-hoc manner; however, this study identified that an interaction can be identified and presumably taught. 
This study recognized the importance of environment in PJDM in ASCg, which should surely therefore be addressed in formal coach training. However the manipulation of parameters in this context appears to be applied from a cognitive perspective. Vickers (2007) notions of a decision training model providing a parsimonious model for these behaviours in this context.

The notion of interaction helps to explain components of the coaching process and furthers our understanding of PJDM. Interactions involve cognitive structures utilising both the knowledge schema (Tannen \& Wallat, 1987) required for the face-to-face, interpersonal coaching encounters and an understanding of the interaction framing/context (Tannen \& Wallat, 1987) in which that knowledge schema is applied. Interactions act as the framework for the practical wisdom. The coaching process is built on both a suitable declarative knowledge (i.e., technical and pedagogic; Collins \& Kusch, 1998) and the connections between that knowledge and the environment. The ability to adapt and be creative requires more than replication of predefined responses; rather, it requires the application of declarative knowledge in creative and flexible ways - a practical knowledge with interactive expertise that is facilitated by PJDM.

\section{Conclusion}

Our findings support our original hypothesis that hierarchical and cross factor themes characterise the interaction of key elements of knowledge in the PJDM of this group of ASCs. By exploiting that interaction, these ASCs manage the impact of a hyper dynamic coaching context in a pragmatic manner. Importantly, these ASCs manipulate constraints in the AS environment from an cognitive position rather than an ecological stance.

The PJDM process is similar to the mixing (i.e., interaction) of primary colours (i.e., the elements of basic knowledge or knowledge schemas essential to the coaching role), which creates an infinite palette of colour (i.e., broad range of coaching approaches). In contrast, contexts requiring a smaller range of colours, or a "recipe coaching" approach, may be less 
dynamic. Unfortunately, however, whilst quicker to develop this approach results in an inherently limited repertoire and possibly a limited retention: There is a routine and pre-set combination of primary colours to produce a simple range of secondary colours. Though this is still an interaction, it is less complex. We contend that many of the courses which we currently observe across sports fall into this category.

Such limitations are far from inevitable, however. Notably, the interaction could be made explicit in training, allowing both the knowledge schemas and context to be reflected throughout the development of coaching skills. In practical terms, the interaction should be developed alongside knowledge schemas from the outset of the coach education process. We suggest that would requires a philosophical shift in coach development from training to education. This could be achieved by ensuring that the various uses of coaching tools and methods are explicitly explored and enunciated, then applied in a critical fashion to a variety of coaching contexts. As coach 2 identified, however, this would also require a shift toward a principle driven rather than rule driven coaching performance. We suggest that this may increase both the perceived and actual benefit of effective coach education among coaches. Once introduced, the interaction allows the knowledge schemas and contextual frame to be developed in relation to one another; in turn, adaptability will develop in response to the context. By contrast, the more typical and routine delivery of coaching practice produces a more consistent — but also fixed and premeditated response - that only may match the challenges of the situation. The use of a smaller, pre-set palate is easier to develop and requires much less thought, but it also restricts the coach's potential to be flexible, adaptive and creative. We continue to explore ways to further develop Technicolor coaching. 


\section{References}

Abraham, A., \& Collins, D. (2011). Taking the next step: Ways forwards for coaching science. Quest, 63, 366-384. doi:10.1080/00336297.2011.10483687

Aronson, J. (1994). A pragmatic view of thematic analysis. The Qualitative Report, 2, 1-3. Retrieved from http://www.nova.edu/ssss/QR/

Axelrod, R. (1976). Structure of decision: The cognitive map of political elites. Princeton, NJ: Princeton University Press.

Boyatzis, R. E. (1998). Transforming qualitative information: Thematic analysis and code development. Thousand Oaks, CA: Sage.

Braun, V., \& Clarke, V. (2006). Using thematic analysis in psychology. Qualitative Research in Psychology, 3, 77-101. doi:10.1191/1478088706qp063oa

Brymer, E., \& Gray, T. (2010). Dancing with nature: Rhythm and harmony in extreme sport participation. Journal of Adventure Education and Outdoor Learning, 9, 135-149. doi:10.1080/14729670903116912

Busch, P., Richards, D., Dampney, C. (2001). Visual mapping of articulable tacit knowledge. Proceedings of the Asia-Pacific Symposium on Information Visualisation, 9, 37-47. Retrieved from http://dl.acm.org/citation.cfm?id=564045

Busch, P., Richards, D., Dampney, C. (2003). The graphical interpretation of plausible tacit knowledge flows. Proceedings of the Asia-Pacific Symposium on Information Visualisation, 24, 37-46. Retrieved from http://dl.acm.org/citation.cfm?id=857085

Cohen, L., \& Manion, L. (1994). Research methods in education (4th ed.). London, United Kingdom: Routledge.

Collins, D., Martindale, A. Burke, V. \& Cruickshank, A. (2014). The Illusion of Competency versus the Desirability of Expertise: Seeking a Common Standard for Support Professions in Sport. Sports Medicine. DOI 10.1007/s40279-014-0251-1 
Collins, H. (2012). Three dimensions of expertise. Phenomenology and Cognitive Sciences, 12, 253-273. doi:10.1007/s11097-011-9203-5

Collins, H. M., \& Evans, R. J. (2007). Rethinking expertise. Chicago, IL: University of Chicago Press.

Collins, H. M., \& Kusch, M. (1998). The shape of actions: What humans and machines can do. Cambridge, MA: MIT Press.

Collins, L., \& Collins, D. (2012). Contextualising the adventure sport coach. Journal of Adventure Education and Outdoor Learning, 12, 81-93. doi:10.1080/14729679.2011.611283

Collins, L., \& Collins, D. (2013). Decision-making and risk management in adventure sports coaching. Quest, 65, 72-82. doi:10.1080/00336297.2012.727373

Collins, L., \& Collins, D. (2014). Integration of in-action reflective practice as a component of professional judgement and decision making in high level adventure sports coaching practice. Journal of Sports Science. doi.10.1080/02640414.2014.953980

Collins, L., Collins, D., \& Grecic, D. (2014). The epistemological chain in high level adventure sports coaches. Journal of Adventure Education and Outdoor Learning., doi: $10.1080 / 14729679.2014 .950592$

Crabtree, B. F., \& Miller, W. L. (1999). Using codes and code manuals: A template organizing style of interpretation. In B. F. Crabtree \& W. L. Miller (Eds.), Doing qualitative research (2nd ed., pp. 163-177). Newbury Park, CA: Sage.

Cromdal, J. (2000). Code-switching for all practical purposes: bilingual organisation of children's play Diss. Linköping Studies in Arts and Science, 233 Linköping: University

Crum, B. J. (1991). 'Sportification' of society and internal sports differentiation. Spel en Sport, (1), 2-7. 
Davids, K., Button, C. and Bennett, S.J. (2008). Dynamics of Skill Acquisition. A ConstraintsLed Approach. Champaign, IL, Human Kinetics.

Denzin, N, K. \& Lincoln, Y, S. (2005). The Sage handbook of qualitative research( $3^{\text {rd }}$ Edition). London. Sage Publications

Fenichel, E., \& Eggbeer, L. (1990). Preparing practitioners to work with infants, toddlers and their families: Issues and recommendations for educators and trainers. Arlington, VA: National Center for Clinical Infant Programs.

Fereday, J., \& Muir-Cochrane, E. (2006). Demonstrating rigor using thematic analysis: A hybrid approach of inductive and deductive coding and theme development. International Journal of Qualitative Methods, 5, 80-92. Retrieved from http://ejournals.library.ualberta.ca/index.php/IJQM/index

Fleming, N. (2002). A Guide to Learning Styles. Retrieved from http//www.varklearning.com> Copyright version 4.1(2002)

Foucault, M. (1991). Discipline and punish: the birth of the prison Harmondsworth: Penguin Books

Gibson, J, J. (1979). The power of thinking without thinking. New York: Little, Brown Gilbert, W., \& Trudel, P. (2004). Roles of the coach: How model youth team sports coaches frame their roles. The Sport Psychologist, 18, 21-43. Retrieved from http://journals.humankinetics.com/tsp

Hatano, G., \& K. Inagaki (1986). Two courses of expertise. Child Development and Education in Japan, 6, 262-272. Retrieved from http://hdl.handle.net/2115/25206 Loland, S. (2007). Outline of a phenomenology of snowboarding. In M. J. McNamee (Ed.), Philosophy, risk and adventure sports (pp. 106-117). Abingdon, United Kingdom: Routledge. 
Loynes, C. (1996). Adventure in a bun. Journal of Adventure Education and Outdoor Learning, 13, 52-57. doi:10.1177/105382599802100108

Lyle, J. (2003). Stimulated recall: A report on its use in naturalistic research. British Educational Research Journal, 29, 861-878. doi:10.1080/0141192032000137349

Marsick, V. J., \& Watkins, K. E. (2001). Informal and incidental learning. New Directions for Adult and Continuing Education, 89, 25-34. doi:10.1002/ace.5

Mascarenhas, D. R. D., \& Smith, N. C. (2011) Developing the performance brain: Decision making under pressure. In, Collins, D., Richards, H., and Button, A. (Eds)., Performance Psychology - A Practitionner's Guide. Elsevier, pp. 245-267.

Martindale, A., \& Collins, D. (2005). Professional judgement and decision making: The role of intention for impact. The Sport Psychologist, 19, 303-317. Retrieved from http://journals.humankinetics.com/tsp

Martindale, A., \& Collins, D. (2007). Enhancing the evaluation of effectiveness with professional judgement and decision making. The Sport Psychologist, 21, 458-474. Retrieved from http://journals.humankinetics.com/tsp

Martindale, A., \& Collins, D. (2010). But why does what works work? A response to Fifer, Henschen, Gould, and Ravizza. The Sport Psychologist, 24, 113-116. Retrieved from http://journals.humankinetics.com/

Miles, M. B., \& Huberman, A. M. (1994). Qualitative data analysis (2nd ed.). London, United Kingdom: Sage.

Morrow, S. L. (2005). Quality and trustworthiness in qualitative research in counselling psychology. Journal of Counselling Psychology, 52, 250-260. doi:10.1037/00220167.52.2.250 
Muir, T., \& Beswick, K. (2007). Stimulating reflection on practice: Using the supportive classroom reflection process. Mathematics Teacher Education and Development, 8, 74-93. Retrieved from http://www.merga.net.au/node/42

Nash, C., Martindale, R., Collins, D., \& Martindale, A. (2012). Parameterising expertise in coaching: Past, present and future. Journal of Sports Sciences, 10, 985-994. doi:10.1080/02640414.2012.682079

Rossi, T., \& Cassidy, T. (1999). Knowledgeable teaching in physical education: A view of teacher's knowledge. In C. Hardy \& M. Mawer (Eds.), Learning and teaching physical education. London, United Kingdom: Falmer.

Saury, J., \& Durand, M. (1998). Practical knowledge in expert coaches: On-site study of coaching sailing. Research Quarterly for Exercise and Sport, 69, 254-266. doi:10.1080/02701367.1998.10607692

Smith, J. A. (2011a). Qualitative psychology: A practical guide to research methods (2nd ed.). London, UK: Sage.

Smith, J. A. (2011b). Evaluating the contribution of interpretive phenomenological analysis. Health and Psychology Review, 5, 9-27. doi:10.1080/17437199.2010.510659

Smith, J. A., Flowers, P., \& Larkin, M. (2012). Interpretative phenomenological analysis: Theory, method and research. London, United Kingdom: Sage.

Sparkes, A. (1998). Validity in qualitative inquiry and the problem of criteria: Implications for sport psychology. The Sport Psychologist, 12, 363-386. Retrieved from http://journals.humankinetics.com/tsp

Sparrman, A. (2005). Video recording as interaction: participant observation of children's everyday life Qualitative Research in Psychology 2(3) 241-255

Spradley, J. P. (1980). Participant Observation London: Harcourt Brace Jovanovich College Publishers 
Tannen, D., \& Wallat, C. (1987). Interactive frames and knowledge schemas interaction: Examples from medical examinations/interviews. Social Psychologist Quarterly, 50, 205-216. doi:10.2307/2786752

Tolman, E. C. (1948). Cognitive maps in rats and men. Psychological Review, 55, 189-208. doi:10.1037/h0061626

Vallerand, R. J. (2004). Intrinsic and extrinsic motivation in sport. Retrieved from http://ess220.files.wordpress.com/2010/12/vallerand-2004-overview.pdf

Vickers, J. N. (2007). Perception, cognition, decision training: The quiet eye in action. Champaign, IL: Human Kinetics.

Zuckerman, M. (1994). Behavioural expressions and biosocial bases of sensation seeking. Cambridge, UK: Cambridge University Press. 